\title{
Vicente Lombardo Toledano y su cruzada obrera continental: entre colaboraciones y conflictos, 1927-1938
}

\author{
Vicente Lombardo Toledano and his working continental crusade: between \\ collaborations and conflicts, 1927-1938
}

\author{
Patricio Herrera González*
}

\begin{abstract}
Resumen: Este artículo proporciona antecedentes nuevos, y en algunos casos inéditos, sobre la colaboración y conflictos que enfrentó Vicente Lombardo Toledano, en su cruzada por alcanzar la unificación de la clase obrera a nivel continental. La participación de Lombardo Toledano, como dirigente e intermediario de los intereses obreros, se sustenta en este trabajo con fuentes de archivo no trabajadas con anterioridad, por tanto presentamos a lo largo del artículo perspectivas nuevas y complementarias a las existentes, que van a contracorriente de la historiografía del movimiento obrero.
\end{abstract}

Palabras clave: Vicente Lombardo Toledano, México, América Latina, comunismo, unificación obrera, colaboración, conflictos.

\begin{abstract}
This article provides new precedents, and in some unpublished cases, on the collaboration and conflicts that Vicente Lombardo Toledano faced, in his crusade for reaching the unification of the working class to continental level. The Lombard's participation Toledano, as leader and intermediary of the working interests, is sustained in this work by sources of file not worked previously, therefore let's sense beforehand along the article new and complementary perspectives to the existing ones, which go to crosscurrent of the historiography of the labor movement.
\end{abstract}

Key words: Vicente Lombardo Toledano, Mexico, Latin America, communism, working unification, collaboration, conflicts.

\section{Introducción}

\footnotetext{
* Chileno. Doctor en Historia, Centro de Estudios Históricos, El Colegio de Michoacán, Zamora, México. Profesor-Investigador en la Facultad de Ciencias Económicas y Administrativas, Universidad de Valparaíso, Chile. Este trabajo se inscribe en el marco del proyecto FONDECYT Iniciación $\mathrm{n}^{\mathbf{0}} 11140839$, dirigido por el autor y patrocinado por la Universidad de Valparaíso (2014-2017). Correo electrónico: patricio.herrera@uv.cl
} 
La realidad obrera continental de América Latina experimentó circunstancias particularmente complejas en la década de 1930, por efectos de los (des)ajustes del orden internacional. El agotamiento del modelo político y socioeconómico liberal, el ascenso de Adolf Hitler a la cancillería de Alemania, en enero de 1933, y la estrategia de cooperación inter-clases ratificada en el VII Congreso de la Internacional Comunista (IC), realizado en Moscú en julio-agosto de 1935, fueron factores que influyeron en el desarrollo de las relaciones entre la clase obrera y el poder político-económico durante esta década, cuestión que intensificó la urgencia de presentar una posición unificada de los sectores obreros del continente para enfrentar el escenario de "crisis" que se "respiraba" en el mundo, como resultado de una inevitable conflagración mundial y las consiguientes restricciones económicas y sociales que recaerían sobre estos sectores.

Esta investigación proporciona antecedentes nuevos, y en algunos casos inéditos, sobre el papel que le correspondió al dirigente sindical mexicano Vicente Lombardo Toledano para consolidar la influencia de la clase obrera a nivel continental. La participación de Lombardo Toledano, como dirigente e intermediario de los intereses obreros, se sustenta en este trabajo con fuentes de archivo no trabajadas con anterioridad, por tanto presentamos a lo largo del artículo perspectivas nuevas y complementarias a las existentes, que van a contracorriente de la historiografía del movimiento obrero ${ }^{1}$. Insistir en la premisa de que Vicente Lombardo Toledano tuvo una trayectoria sindical que sólo se materializó por la "designación" del presidente Lázaro Cárdenas; afirmar sin fuentes directas su carácter de "agente de inteligencia" de los soviéticos; incluso asegurar que fue el "principal representante de la Comintern en México" ${ }^{2}$ y para América Latina, como líder de la Confederación de Trabajadores de América Latina (CTAL), dan cuenta de los estereotipos que todavía permanecen en los estudios. Esto no ha permitido, a nuestro juicio, ponderar las virtudes, límites y conflictos que supuso el trabajo sindical y político del dirigente mexicano y latinoamericano, cuestión que hemos procurado ir dilucidando en estudios anteriores ${ }^{3}$.

\footnotetext{
${ }^{1}$ Al respecto véase Patricio Herrera González, "La Confederación de Trabajadores de América Latina en la historiografía obrera, 1938-1963”, Cuadernos de Historia, núm. 36, 2012, pp. 85-117.

${ }^{2}$ Por citar un ejemplo, Olivia Gall en sus investigaciones sobre Trotsky construye un estereotipo sobre los vínculos de Lombardo Toledano con el comunismo, siendo sus referencias las memorias y obras completas de León Trotsky, no cita fuentes disponibles en el FHLT o RGASPI. Al respecto O. Gall, "El papel del PCM y Lombardo en la guerra del Kremlin, la Comintern y la GPU contra Trotsky, México 1936-1940”, pp. 615-651, Elvira Concheiro, Massimo Modonesi y Horacio Crespo (Coord.), El comunismo: otras miradas desde América Latina, México, UNAM, 2007.

${ }^{3}$ Véase de nuestra autoría: "En favor de una Patria de los trabajadores". La Confederación de Trabajadores de América Latina y su lucha por la emancipación del continente, 1938-1953. Tesis de Doctor en Historia, Centro de Estudios Históricos, El Colegio de Michoacán, Zamora, México, 2013 (Inédita); "Vicente Lombardo Toledano: nexo entre los obreros latinoamericanos y la OIT”, Trabajadores, núm. 91, 2012, pp. 23-29; "La primera conferencia regional del trabajo en América: su influencia en el movimiento obrero, 1936”, pp. 199-242, Fabián Herrera León y Patricio Herrera González (Coord.), América Latina y la Organización Internacional del Trabajo. Redes, cooperación técnica e institucionalidad social, 1919-1950, Morelia, México, Instituto de Investigaciones Históricas, Universidad Michoacana de San Nicolás de Hidalgo, 2013; "El pacto por la unidad obrera continental: sus antecedentes en Chile y México, 1936", Estudios de Historia Moderna y Contemporánea de México, núm. 46, 2013, pp. 87-119; "La Confederación de Trabajadores de América Latina y la implementación de su proyecto sindical continental (1938-1941)”,
} 
Creemos, que la historiografía mexicana y mexicanista aún no se (re)encuentra con la trayectoria de Lombardo Toledano como sindicalista, intelectual y político. $\mathrm{Ni}$ en su modalidad mexicana, menos en su versión continental, el dirigente todavía es desconocido en sus múltiples facetas. Al respecto, hay numerosas investigaciones que reconocen el protagonismo de Lombardo Toledano, sin embargo no hay una sistematicidad en registrar sus logros, negociaciones y fracasos. Los estudios subrayaron algunas perspectivas ideológicas o acciones estratégicas, que no permiten establecer cabalmente el desempeño del dirigente en México y el continente. Al contrario, en sus hombros acumula sentencias políticas, doctrinarias y militantes de una historiografía que lo responsabiliza de los fracasos de la izquierda mexicana, de prácticas políticas "impuras" en relación con el Partido Comunista Mexicano (PCM) o de sus limitados compromisos democráticos hacia sus representados, como resultado de su "empedernida maniobra" y componendas políticas. Hechos que merecen mayor atención, y que en este artículo tratamos de matizar.

Las representaciones sobre Lombardo Toledano se han mantenido en forma inalterable por décadas, sin que existan estudios que renueven las interpretaciones de sus intervenciones políticas. El ya clásico estudio de E. Krauze, sobre la contribución de Lombardo Toledano en el contexto de la cruzada cultural que desarrolló durante la Revolución Mexicana o las investigaciones que puntualizaron su papel en la Confederación de Trabajadores de México (CTM), como los de A. Anguiano, A. Córdova o F. Chassen, por señalar algunos autores, proporcionaron antecedentes relevantes, pero sin puntos de comparación con las fuentes disponibles en el presente. La consulta de archivos, Fondo Histórico Lombardo Toledano (FHLT), Archivo Estatal Ruso de la Historia Social y Política (RGASPI) o Archivo de la Organización Internacional del Trabajo (AOIT), permite reconstruir líneas de pensamiento y acción en colaboración y conflicto, particularmente en su versión más influyente para México y América Latina, como fueron las décadas de 1930 y 1940, cuestiones que se plantean y acentúan en este artículo.

\section{Vicente Lombardo Toledano y la emergencia de su liderazgo}

La experiencia política y sindical de Vicente Lombardo Toledano, desde muy joven, fue marcada por un doble proceso histórico, ejecutados en forma simultánea, la Revolución mexicana y el permanente asedio de la intervención estadounidense en la política interna del país. En 1927, ante una violenta controversia entre el gobierno de México y de Estados Unidos por la expedición de una ley sobre el petróleo, la representación de la Confederación Regional Obrera Mexicana (CROM) propuso la revisión completa del estatuto de la Confederación Obrera Panamericana (COPA), organización coordinada y financiada por la Federación Americana del Trabajo (AFL) y que estaba al servicio de la

Trashumante, núm. 2, 2013, pp. 136-164; "Vicente Lombardo Toledano y el Congreso Obrero Latinoamericano (1935-1938)", Relaciones, núm. 138, 2014, pp. 109-150. 
política exterior de Estados Unidos. En esa oportunidad, reunidos los obreros mexicanos en el Teatro Esperanza Iris de la Ciudad de México, el 30 de enero de 1927, Vicente Lombardo, único orador, denunció las ambiciones de dominación de Estados Unidos sobre América Latina, llamó a la clase trabajadora, sin excepciones, de todo el continente a combatir la ideología del panamericanismo y la doctrina Monroe, propugnadas por el imperialismo ${ }^{4}$. Se trató, seguramente, de una idea no ponderada del todo, surgida al calor del encendido discurso, sin poseer aún un proyecto definido de unidad, pero que discernía los derroteros para combatir a los enemigos de Latinoamérica y acaso el inicio de su trayectoria como dirigente del proletariado continental.

El dirigente mexicano tuvo muy claro que, tanto para su país como para el continente, se necesitaba luchar por la formación de un nacionalismo revolucionario dentro de la clase explotada, como condición previa para la transformación social. En su estrategia se contempló la necesidad de que la clase política en alianza con las clases productivas, industriales y obreros, controlaran las riquezas nacionales, para promover un mejor bienestar y lograr una autonomía económica plena, que erradicara definitivamente el imperialismo en el continente. Incluso se propuso concretar esfuerzos constantes a favor y en solidaridad con las víctimas de la lucha revolucionaria contra el capitalismo por encima de las fronteras nacionales. Así lo señaló explícitamente, en marzo de 1933: "La CROM convocará a todas las agrupaciones obreras de las naciones iberoamericanas a un congreso para la organización de la Confederación Obrera Iberoamericana, que discutirá y aprobará, un programa de defensa y de acción contra el imperialismo de América"5.

Entre 1932-1933 la CROM se atomizó, cuando las pugnas políticas de las facciones existentes en su interior desencadenarían la más importante ruptura de la primera organización unitaria de los obreros mexicanos. El monopolio del poder entre los cromistas siguió en manos del dirigente Luis N. Morones, aliado de W. Green, líder de las organizaciones sindicales AFL y COPA.

La tendencia lombardista, opositora al liderazgo de Morones, se retiró de la CROM. La mayoría de estas organizaciones sindicales aprobaron un nuevo programa de acción, redactado por Lombardo Toledano, dando vida a la Confederación General de Obreros y Campesinos de México (CGOCM) en el mes de octubre de 1933, que entre sus orientaciones principales tomó la resolución de cooperar para la "unidad de los trabajadores de la América Latina"6.

\footnotetext{
4 Vicente Lombardo Toledano, La Doctrina Monroe y el Movimiento Obrero, México, Talleres Linotipográficos La Lucha, 1927.

${ }^{5}$ Programa mínimo de acción de la CROM, presentado por Vicente Lombardo Toledano el 20 de marzo de 1933 como Secretario General de la CROM, en Vicente Lombardo Toledano (en adelante VLT), Obra Histórico-Cronológica, tomo II, volumen 4, México, Centro de Estudios Filosóficos, Sociales y Políticos Vicente Lombardo Toledano, 1995, p. 78.

${ }^{6}$ Declaración de principios de la CGOCM, en VLT Obra Histórico-Cronológica, Tomo II, Volumen 4 op. cit., p.232.
} 
La entronización en el poder del general Lázaro Cárdenas supuso una renovación política en la administración del Estado mexicano, acentuando el ideario de transformación social, encauzando los principios revolucionarios de 1910, que de una u otra forma se fueron relegando por las guerras intestinas entre las diversas facciones de caudillos o simplemente por los vicios del poder de las armas en tiempos de borrasca.

Plutarco Elías Calles, el otrora líder sonorense y "Jefe Máximo" de la Revolución, fue junto a sus seguidores un firme opositor a la política cardenista, cuestionando su plan de gobierno. El presidente Cárdenas con su discurso marcadamente antiimperialista denunció la ausencia de transformaciones estructurales de corte revolucionario y alimentó la necesidad de constituir un movimiento nacional de masas. En una entrevista realizada en abril de 1935, en plena efervescencia social, Lázaro Cárdenas expresaba su compromiso con la clase trabajadora, sosteniendo que se debía "combatir al capitalismo, a la escuela liberal capitalista que ignora la dignidad humana en los trabajadores y los derechos de la colectividad", pero a su vez exteriorizó su respeto y estímulo del gobierno hacia el capital que se ajustaba "a las nuevas normas de justicia distributiva, que garantiza buenos salarios y cumple los derechos esenciales de las clases trabajadoras"?

Vicente Lombardo Toledano, en un principio dudó de la independencia política y talante revolucionario de Lázaro Cárdenas ${ }^{8}$. A poco andar cambió sus primeras impresiones porque el general inició un programa de gobierno que acentuaba el carácter revolucionario, para devolver las esperanzas a la clase obrera y campesina que continuaban marginados de los beneficios sociales y económicos del proceso iniciado en 1910.

Las críticas de P. E. Calles al presidente Cárdenas, por los medios de comunicación afines al callismo (Novedades, Excélsior), por su decisión de no reprimir a los sindicatos obreros en huelga, en varios estados de la República, tuvo un vuelco inesperado. La CGOCM y el Partido Comunista Mexicano (PCM), por indicaciones de la Profintern, expresaron su apoyo al mandatario e iniciaron su defensa ante las agresiones de la oposición callista. Lombardo Toledano tuvo presente que la unidad de los obreros mexicanos era esencial para garantizar sus derechos sociales, pero aquello sólo se alcanzaría, sentenciaba el dirigente, si el régimen de gobierno se reformaba por completo, estableciendo una socialización de los medios de producción y colaborando junto a las organizaciones sindicales a "formar la conciencia de clase del proletariado".

\footnotetext{
${ }^{7}$ Cárdenas antes los problemas de México, entrevista Cárdenas-Padilla, 12 de abril de 1935, México, D. F., Comité de Orientación Popular, 1935, p. 8.

${ }^{8}$ Vicente Lombardo Toledano, "El derrumbamiento del general Plutarco Elías Calles", manuscrito, julio de 1935, FHLT, Id. 15857, legajo 265.

${ }^{9}$ Discurso de Vicente Lombardo Toledano pronunciado ante la convención extraordinaria de la CROM, el 12 de marzo de 1933, VLT, Obra Histórico-Cronológica, tomo II, Volumen 4 op. cit., pp. 66-87. Para contextualizar la época señalada, véase a Arturo Anguiano, El Estado y la política obrera del cardenismo, México, Era, 1975; Arnaldo Córdova, La política de masas del cardenismo, México, Era, 1974; Arnaldo Córdova, La clase obrera en la historia de México: en una época de crisis (1928-1934), México, Siglo XXI editores, 1980; Samuel León e Ignacio Marván, La clase obrera en la historia de México: en el Cardenismo (1934-1940), México, Siglo XXI editores, 1985.
} 
La participación explícita de P. E. Calles en la política contingente fue un factor que logró conformar un frente obrero unido, en parte ello facilitó la instrumentación del proyecto político de Lázaro Cárdenas y de paso acrecentó el liderazgo e influencia de Lombardo Toledano en las organizaciones obreras y campesinas, más allá de la CGCOM. La alianza política entre ambos permitió contener a los "enemigos de la Revolución" y fortalecer la política transformadora del gobierno.

Ante las amenazas flagrantes de Calles, en la mañana del 12 de junio de 1935 el Sindicato Mexicano de Electricistas (SME) invitó a diferentes organizaciones y sus representantes para discutir la posición de la clase obrera en estas circunstancias. Lombardo Toledano, al frente de la CGOCM, la Confederación Sindical Unitaria de México (CSUM), bastión del PCM, y varios sindicatos independientes, excepto la CROM y la Confederación General de Trabajadores (CGT) - partidarios de P. E. Calles -, asistieron sin retraso a la cita. Ahí discutieron con vehemencia sus propuestas, resolviendo constituir el Comité Nacional de Defensa Proletaria $(\mathrm{CNDP})^{10}$. En la calle República de Colombia número 9, domicilio social del SME, el 15 de junio se llevó a cabo un pacto de solidaridad de las organizaciones obreras para defenderse de los ataques por la prensa del expresidente Calles, y ante el temor de acciones represivas de sus simpatizantes, quienes expresaban su descontento por las huelgas y mítines de los trabajadores en toda la República.

Las acciones del gobierno Federal en favor de las "masas" obreras contribuyó a consolidar los lazos entre obreros y campesinos y de paso reafirmó la ruta "reformista estructural" de la administración cardenista. Entre los dirigentes que coordinaron el CNDP podemos mencionar, entre otros, a: Francisco Breña Álvarez, Manuel Paulín Ortiz, Valentín Campa, Hernán Laborde, Vicente Lombardo Toledano, Fidel Velázquez, Juan Téllez. En cuanto a las organizaciones obreras participantes podemos mencionar: Alianza de Obreros y Empleados de la Compañía de Tranvías de México S. A; Alianza de Uniones y Sindicatos de Artes Gráficas; Cámara Nacional del Trabajo de la República Mexicana; CGOCM; CSUM, Federación de Obreros y Empleados de la Compañía de Tranvías; Sindicato de Trabajadores Ferrocarrileros de la República Mexicana, Sindicato de Trabajadores Mineros y Metalúrgicos y el SME.

Ocho puntos fueron los que contemplaron las demandas, destacando el objetivo de establecer la unificación del movimiento obrero y campesino a escala nacional con la creación del CNDP, e invitando a todas las agrupaciones populares a adherirse a dicho pacto. Los puntos comunes y centrales fueron la creación de un programa a realizar mediante la satisfacción de las demandas reivindicativas de los trabajadores y, por otro lado, sentar las bases de la unificación obrero-campesina. Este fue el origen de la Confederación de Trabajadores de México (CTM) en el congreso efectuado en febrero de 1936, en la ciudad de México, que si bien no tuvo el efecto político proyectado, produjo una convergencia de posiciones sindicales diversas, que hasta entonces se habían opuesto a

\footnotetext{
${ }^{10}$ Véase Samuel León, "El comité nacional de defensa proletaria”, Revista Mexicana de Sociología, vol. 40, núm. 2, 1978, pp. 729-762.
} 
la intervención del Estado en los sindicatos, y trabajó sin descanso por consolidar la unidad de los obreros mexicanos en una sola gran organización sindical que debía defender los intereses de la clase trabajadora, al gobierno de Cárdenas y frenar la intervención callista en el escenario político nacional, quien fue conminado por el presidente Lázaro Cárdenas a abandonar el país en la madrugada del 10 de abril de 1936.

\section{El Viaje a la URRS: "el mundo del porvenir"}

Mientras se iniciaban los preparativos para alcanzar la unidad del proletariado y la alianza con otras fuerzas, intelectuales, estudiantes y profesionistas, Lombardo Toledano viajó a Moscú y Europa, invitado por la unión de sindicatos soviéticos y con el patrocinio de Rafael Alberti, María Teresa León y los jerarcas de la IC, entre los meses de julio a octubre de $1935^{11}$. El viaje reforzó su convicción de liderar las transformaciones de la clase obrera, lo cual contribuyó a reafirmar su ascendencia entre sectores populares y progresistas de México y coadyuvó a su anhelo de favorecer la unidad del proletariado en América Latina, pues las fuerzas obreras de México y el PCM prestaron su apoyo en forma unánime al proyecto de un "Frente Popular" mexicano, que posteriormente debía promover la unidad continental.

Lombardo Toledano tuvo una gran expectativa por el viaje a la Unión Soviética y Europa, particularmente a Francia y España. Unos días antes de partir, manifestó en una entrevista que siempre había querido visitar la URSS, afirmando que el viaje obedecía a la "urgencia que tiene la organización obrera a la que pertenezco, la Confederación General de Obreros y Campesinos de México, de conocer de un modo directo la situación que guarda la clase trabajadora en Europa. Esta urgencia es mayor que nunca ante el peligro cada más grave de una nueva guerra internacional" ${ }^{12}$.

Una de sus preocupaciones en la preparación del viaje fue el financiamiento. Entre sus papeles personales existe evidencia para sostener que el dinero que le permitió solventar el viaje y la estadía provino de dos fuentes. La primera, fue resultado de un préstamo personal que recibió del Licenciado Salvador Martínez de Alva, destacado funcionario del servicio exterior mexicano. En la carta, Lombardo Toledano le indicó al diplomático que el objetivo de su viaje era estudiar bien la situación de Rusia, pues tenía la intención de escribir un libro "didáctico, imparcial y objetivo, que sirva para conocer la realidad y no para hacer propaganda torpe ni tampoco calumnia vil de la que estoy muy lejos, pues usted sabe con cuanta simpatía seguimos el movimiento de Rusia los que nos preocupamos por las cuestiones humanas"13. Aunque en la correspondencia con Martínez de Alva no se detalla el monto, Lombardo Toledano le aseguró la devolución íntegra del mismo, afirmando: "antes del fin del presente año devolveré a usted el dinero que ha tenido la bondad de enviarme. Lo recibí como un préstamo; de otro modo no lo aceptaría; pero pronto habré

\footnotetext{
11 “Itinerario del viaje de los 100 días (13 de julio-20 de octubre) 1935”, FHLT, manuscrito, legajo 265.

${ }^{12}$ FHLT, Id. 15681, legajo 265. La entrevista se encuentra en El Machete (México), 10 de julio de 1935.

${ }^{13}$ Carta de Vicente Lombardo Toledano dirigida a Salvador Martínez de Alva, México, D. F., 10 de julio de 1935, FHLT, Id. 15702, legajo 265.
} 
vendido los derechos que tengo sobre la casa en que vivo y me sentiré más libre que hoy en cierta forma"14.

La segunda fuente de financiamiento emanó de la Secretaría de Economía Nacional. Ya iniciado el viaje, con primera estancia en Leningrado, Lombardo Toledano recibió una carta del subsecretario de Economía, Ing. Santillán, quien le indicaba que la repartición pública "le comisionaba para estudiar la organización y funcionamiento de cooperativas en la URSS y en otros países europeos [...] teniendo en cuenta el trabajo profesional que como especialista va usted a realizar y la probable duración del mismo, se pagarán a usted Dls. 3000.00 (tres mil dólares) como honorarios" ${ }^{\prime 2}$. Si bien se trata de una suma importante para una estadía de dos meses en Rusia, Francia, Suiza y España, seguramente recibió un apoyo logístico significativo por parte de los dirigentes obreros de aquellos países.

Los jerarcas de IC estaban muy interesados en la visita de Lombardo Toledano, pues su ascendencia sobre la clase obrera y campesina mexicana, sus vínculos con la élite dirigente y política de su país, la estrecha relación con dirigentes sindicales de Estados Unidos y las redes que había construido con la intelectualidad latinoamericana lo catapultaban como el hombre indicado para cohesionar en un frente único a los sectores populares y mesocráticos de tendencia progresista. Su independencia partidista, la que defendió en una entrevista concedida al periódico del PCM, El Machete ${ }^{16}$, y el respeto conseguido por miembros de diversas tendencias ideológicas fue un capital político que la dirigencia de la Profintern valoró en Lombardo Toledano, situándolo, a su regreso del viaje, en el principal portavoz para instaurar un Frente Popular en México, lo cual le produjo numerosos conflictos con los dirigentes del PCM, pues no hubo un apoyo irrestricto de los miembros de la colectividad hacia la persona de Lombardo, denostando, al menos desde 1929, su "marxismo intelectual" y su "falsa representación" del proletariado mexicano a través de las páginas de El Machete. Ante lo cual Lombardo Toledano, y sus colaboradores, acusaba al PCM de "sectarismo" y "divisionismo", utilizando la prensa gobernante, El Universal, o su plataforma propagandista, la revista Futuro $^{17}$.

En la cuna del comunismo pudo "respirar" el "mundo del porvenir", conocer, a su juicio, la vida cotidiana de sus habitantes, comprender la organización política, comprobar los "progresos económicos" y compartir sus experiencias sindicales con dirigentes locales. También se entrevistó con los líderes comunistas que participaban en el VII Congreso de la IC, donde tuvo un encuentro con los delegados del $\mathrm{PCM}^{18}$, lo que terminó por reafirmar sus

\footnotetext{
${ }^{14}$ Ibidem.

${ }^{15}$ Carta de Xavier Icaza a Vicente Lombardo Toledano, México, D. F., 31 de julio de 1935, FHLT, Id. 15851, legajo 265.

${ }^{16}$ El Machete, 10 de julio de 1935. En la entrevista afirmó "esa independencia debe mantenerse de uno modo constante", FHLT, Id. 15681, legajo 265.

${ }^{17}$ Sería largo enumerar las disputas por los medios, se inician al menos desde 1929, pues excede los límites de este artículo. Sin embargo, es relevante indicar que falta realizar un estudio detallado de la batalla ideológica en la prensa de la época.

${ }^{18}$ Véase Daniela Spenser, “El viaje de Vicente Lombardo Toledano al mundo del porvenir”, Desacatos, núm. 34, 2010, pp. 77-96.
} 
convicciones sobre la necesidad de concretar la unidad del proletariado mexicano y latinoamericano. Al escribir sus primeras impresiones del viaje manifestó hallarse absorto, conmovido por ver la materialización del socialismo, subrayando la disposición a redoblar su trabajo en "favor de la revolución proletaria, con más ardor que nunca, con nueva fe, con el estímulo que dan los sueños o las esperanzas que se cumplen"19.

Unos meses después, con mayor reposo y reflexión, las ideas se decantaron en una serie de conferencias en el Teatro Hidalgo en la ciudad de México dirigidas al público en general los primeros días del mes de noviembre de 1935, publicadas luego bajo el título de Un viaje al mundo del porvenir. En sus páginas Vicente Lombardo manifestó explícitamente su apoyo a la Unión Soviética y exhortó al proletariado mexicano para hacer de la "humanidad la especie que ha de dominar el planeta en el sentido de la dicha colectiva, invocando siempre la concepción marxista-leninista del universo: los militantes mexicanos tenemos que poner nuestro entusiasmo en la creación de una humanidad mejor, empezando por el territorio en que vivimos" 20 .

Ya reintegrado a la vida pública y contingente en suelo mexicano "luchó con mayor entusiasmo que nunca" a favor de la unidad del proletariado de México y de América Latina $^{21}$, al menos así lo manifestó en reiteradas oportunidades, dada las condiciones de asedio contrarrevolucionario que enfrentaba el gobierno del general Cárdenas. Las fuerzas sediciosas de Calles, apoyadas por los cromistas y los "Camisas Doradas",22, su brazo armado, estaban dispuestos a desestabilizar al gobierno, pues temían que las reformas "socialistas" aproximaran a México a la hegemonía comunista de la URSS. Las sospechas del callismo, sobre el giro izquierdista del cardenismo, se alimentaron por la recepción que dieron los militantes comunistas a Lombardo Toledano cuando regresó del viaje por Europa y la Unión Soviética, cuestión que el dirigente consideró como una estrategia errada del PCM para conseguir la unidad de los obreros mexicanos y el apoyo al presidente Cárdenas.

\section{La unidad del proletariado mexicano se materializa}

La fundación de la Universidad Obrera, el 8 de febrero de 1936, fue un primer paso para consolidar la unidad y defensa del proletariado mexicano ${ }^{23}$. Fue concebida por Vicente

19 Vicente Lombardo Toledano a Benjamín Tobón, Moscú, 13 de septiembre de 1935, Colección de Manuscritos Generales 238, Archivos Nacionales de Washington, caja 15, exp. 598, Daniela Spenser, "Unidad a toda costa": La Tercera Internacional en México durante la presidencia de Lázaro Cárdenas, México, CIESAS, Publicaciones de la Casa Chata, 2007, p. 176.

${ }^{20}$ Vicente Lombardo Toledano y Víctor Manuel Villaseñor, Un viaje a un mundo del porvenir (Seis conferencias sobre la U.R.S.S.), México, Universidad Obrera de México, 1936, p. 159. También, resulta interesante la conferencia que dieron Víctor Manuel Villaseñor y Vicente Lombardo Toledano en París, el 2 de octubre de 1935, titulada: "Situación de la clase trabajadora de México e impresiones de nuestro viaje a la URSS”, FHLT, Id. 15584, legajo 267. La fuente no indica en qué lugar de París ofrecieron esta conferencia.

${ }^{21}$ Vicente Lombardo Toledano a Alexander Losovsky, México, 15 de abril de 1937, RGASPI, fondo 495, serie 108, exp. 198, MP-48.12

22 “Campaña de seis meses que desarrollará Acción Revolucionaria Mexicana Los Dorados”, México, D. F., 1 de diciembre de 1935, FHLT, manuscrito, legajo 269.

${ }^{23}$ Vicente Lombardo Toledano proyectó inicialmente un "Colegio Obrero Mexicano", para la "formación de cuadros del movimiento obrero", idea que expuso en la VI Conferencia Nacional de la CROM, noviembre de 
Lombardo como un referente intelectual para la clase obrera de México. Desde sus aulas se proyectó la formación de una vanguardia de los trabajadores, portadores de las "ideas que han de presidir el mundo futuro" 24 . Este centro de estudios fue considerado un "hogar proletario", un espacio de convivencia de obreros manuales e intelectuales, que reflexionaría sobre la realidad nacional e internacional. Incluso el líder sindical pensó que la congregación de los obreros en sus patios era la antesala "para marchar perfectamente de acuerdo"25. Lombardo Toledano creyó que la Universidad Obrera de México realizaría una gran labor, muy potente, favoreciendo la conciencia nacionalista, pero no "patriotera, no snobista, no formal: de fondo, revolucionaria de verdad, porque tratamos de darle patria a quienes no la tienen todavía, y hacer que la enseña nacional, la bandera tricolor, pueda hermanarse definitivamente en el esfuerzo y en el anhelo, a la bandera roja del proletariado" 26 .

La universidad fue un centro de reuniones de los principales dirigentes sindicales de México. Desde sus instalaciones salieron muchas de las cartas, telegramas y comunicados de prensa que tuvieron como objetivo estrechar los nexos entre los líderes obreros del continente, para concretar la unidad obrera de América Latina y el Caribe. También, fue en ese espacio que se denunció a través de la prensa, mexicana o continental, a los gobiernos de la región que reprimían a las organizaciones de trabajadores o restringían los derechos políticos de los pueblos. Lombardo Toledano consiguió que la Universidad Obrera de México fuese un referente en materia laboral y sindical, muchas de las publicaciones de la CTM, y posteriormente de la CTAL, fueron impresas por la institución, en parte tuvo numerosos éxitos en hacer circular sus impresos, sin embargo faltan mayores estudios que evalúen su influencia en México y América Latina ${ }^{27}$.

1924, Ciudad Juárez, Chihuahua. El proyecto con su fundamentación teórica, cuerpo de profesores y plan de estudios se publicó en CROM, núm. 28, 15 de abril de 1926, pp. 35-47. Un ejemplar mecanografiado se encuentra en el Archivo Histórico, El Colegio de Michoacán, Fondo Enrique Arreguín Vélez, caja 5, exp. 8. Posteriormente, en el mes de julio de 1932 Vicente Lombardo Toledano estaba proyectando un espacio académico para los jóvenes obreros, así lo expresó en una carta a Alfonso Reyes: "Me propongo organizar [...] una escuela importante para adoctrinar a los obreros jóvenes, la generación actual está podrida y necesitamos preparar nueva gente para mañana, cuando México se vea obligado a seguir la corriente renovadora, que la impondrá el mundo exterior, porque no creo en nuestra renovación mexicana por muchos años", carta de Vicente Lombardo Toledano a Alfonso Reyes (Embajador de México en Brasil), ciudad de México, 25 de julio de 1932, FHLT, Id. 11382, legajo 202. Adicionalmente mantuvo contactos con funcionarios de la Oficina Internacional del Trabajo, por ejemplo con Adolf Staal, jefe de Relaciones Obrera, al cual solicitó información sobre proyectos de universidades obreras en Europa. Al respecto véase AOIT, Vicente Lombardo Toledano a Adolf Staal, ciudad de México, 28 de febrero de 1933, Exp. I-B12; AOIT, Adolf Staal a Vicente Lombardo Toledano, Ginebra, 29 de marzo de 1933, Exp. I-B12;

${ }^{24}$ Discurso de Vicente Lombardo Toledano en la inauguración de la Universidad Obrera de México, pronunciado el 8 de febrero de 1936, CTM 1936-1941, México, 1941, p. 83.

${ }^{25}$ Ibid., p. 85.

${ }^{26}$ Ibid., p. 86.

${ }^{27}$ En el presente se requiere de una investigación sistemática sobre la formación de los cuadros sindicales de México y América Latina en la Universidad Obrera de México. El FHLT conserva toda la documentación al respecto. 
Al constituirse el Congreso Nacional de Unificación Proletaria (CNUP), la semana del 19 al 26 de febrero de 1936, su asamblea discutió y enfatizó la necesidad de concretar la unidad obrera continental. Fue evidente que las condiciones internacionales y las demandas obreras de cada uno de los países latinoamericanos estaban acumulando descontento y un poder de convocatoria, como nunca antes se había experimentado. Los populismos y autoritarismos experimentados en Brasil, Paraguay, Bolivia, Argentina, Nicaragua, Guatemala, fueron motivo de preocupación de dirigentes obreros mexicanos. Se hablaba del fascismo de Vargas en Brasil, la amenaza de la sedición y el anticomunismo en Argentina, Chile y Perú. Eran tiempos inciertos y por eso los llamados desde el CNUP no se hicieron esperar: "Creada la central sindical única de México es preciso que este poderoso número de trabajadores inicie los trabajos necesarios para procurar la unificación de los trabajadores sindicalizados de la América Latina"28.

Los temores ante la reacción imperialista estadounidense, particularmente luego de la expropiación petrolera decretada el 18 de marzo de 1938, y la oposición de los "renegados" de la Revolución Mexicana -como lo fueron Saturnino Cedillo o Juan Almazán en las postrimerías del gobierno de Lázaro Cárdenas- además de las fuerzas conservadoras tradicionales, fueron una fuente de preocupación que detonó la necesidad de congregar a todas las agrupaciones obreras, intelectuales, periodísticas e industriales para reafirmar su compromiso con el nacionalismo revolucionario y la defensa de la gestión política del general Cárdenas:

Llegará el momento, camaradas, en que el proletariado de nuestro país, que representa la poderosa Confederación que acabamos de organizar, denuncie a todos los que en alguna forma, participando directa o indirectamente con el gobierno de Cárdenas tratan de establecer en nuestro país una dictadura de tipo burgués, con tendencia a una organización fascista que pudiera vincularse a otras de los países latinoamericanos [...] No vamos a establecer la dictadura del proletariado; no vamos a estar haciendo demagogia $u$ ofrecimientos, como esta gente cree que podemos hacerlo; vamos a robustecer la conciencia de la masa oprimida ${ }^{29}$.

El sector laboral radical sintió, como tantas otras veces, las amenazas de sus vecinos del Norte, a las que debieron sumarse en esos momentos los fundados temores hacia sus "camaradas" del sur. Puede afirmarse que la situación de las organizaciones sindicales de toda América Latina fue inestable y que sólo la unión de todas las agrupaciones podía salvarlos de "nuevas privaciones y de otras etapas de grandes sacrificios", puntualizaban algunos dirigentes obreros mexicanos ${ }^{30}$.

\footnotetext{
${ }^{28}$ Resolución del segundo congreso de la CGOCM para asistir al Congreso Nacional de Unificación Proletaria, 19 de febrero de 1936, en VLT, Obra Histórico-Cronológica, tomo III, volumen 4, México, Centro de Estudios Filosóficos, Políticos y Sociales Vicente Lombardo Toledano, 1996, p. 61.

${ }^{29}$ Discurso de Vicente Lombardo Toledano, pronunciado al clausurarse los trabajos del Congreso Nacional de Unificación Proletaria, 24 de febrero de 1936, en CTM, op. cit., pp. 61-65

${ }^{30}$ Propuesta presentada por Vicente Lombardo Toledano, Salvador Rodríguez L., y Francisco Breña al Congreso Nacional de Unificación Proletaria el 24 d febrero de 1936, en CTM, op. cit., p. 53.
} 
Al quedar formada la tercera gran central sindical, la CTM, su asamblea constituyente acordó convocar a un congreso a todos los trabajadores de América Latina para formar con ellos un amplio frente sindical internacional que lucharía por la unidad de los obreros en cada centro de trabajo, en cada rama de la producción y de los servicios, en cada país y a lo largo del continente. Al respecto, se reconoció que el movimiento obrero mexicano "pondrá todo lo que esté de su parte para lograr la unidad internacional del movimiento del proletariado organizado [...] luchará, organizada y sistemáticamente, hasta eliminar todos los obstáculos que estorben la obtención de sus objetivos ${ }^{\text {”31 }}$.

Al fundar la Universidad Obrera y la CTM, Lombardo Toledano procuró que la clase obrera mexicana estuviese conformada por todos los sectores representativos de las ramas productivas, de tal forma que aquello asegurara la conquista de sus derechos políticos y sociales. De ahí la demanda histórica y coyuntural, considerando el escenario de confrontación política en México, para implementar una fuerte organización obrera internacional que defendió Lombardo, con mayor ímpetu desde 1936, facilitada en parte por el contexto político en la acción nacionalizadora de Lázaro Cárdenas. Además, fue un hecho reconocido en la época que México estaba consiguiendo una preponderancia en varios países del continente. Por ejemplo, en Argentina, Chile y Ecuador se formaron asociaciones de "Amigos de México", y la prensa en general consideró al país como ejemplo de lucha nacional y antifeudal: "Cárdenas se está haciendo de gran prestigio en los sectores avanzados del Continente. Este hecho, que estimula y fortalece la lucha nacional revolucionaria de América Latina, cobra más fuerza con la actividad de la CTM por la unificación obrera continental" ${ }^{\text {32 }}$. Un ejemplo del legado de la obra del presidente Lázaro Cárdenas fue la difusión que tuvieron sus reformas, particularmente en favor de campesinos y obreros, en la revista Rumbo, órgano de la Juventud del Partido Socialista de Chile ${ }^{33}$. Incluso Juan Barzelatto, Secretario Gral. de la Brigada Socialista Universitaria de Chile, escribió a Vicente Lombardo Toledano para solicitar una colaboración para la revista ${ }^{34}$.

\section{Lombardo Toledano y las tensiones entre la Profintern y el PCM}

Tempranamente el PCM, a través de emisarios internacionales, inició entrevistas para informarse, y tratar de incidir, sobre la planificación del Congreso obrero. A finales del mes de abril de 1936, en vísperas del primero de mayo, Witold Antonovich Lovsky ${ }^{35}$,

\footnotetext{
${ }^{31}$ Estatutos de la Confederación de Trabajadores de México, en CTM, op. cit., pp. 66-80.

32 Informe [posiblemente escrito por Hernán Laborde] sobre la fundación de la Confederación de Trabajadores de México, la política de Lázaro Cárdenas y sus consecuencias para México y América Latina, enviado al Comintern, 2 de junio de 1936, RGASPI, fondo 495, serie 108, exp. 185, MP-48.12.

${ }^{33}$ Rumbo, núm. 4, 1939, pp. 248-250.

${ }^{34}$ Carta de Juan Barzelatto a Vicente Lombardo Toledano, Santiago, 17 de junio de 1936, FHLT, Id. 16478, legajo 280; carta de Vicente Lombardo Toledano a Juan Barzelatto, ciudad de México, 7 de enero de 1937, FHLT, Id. 16756, legajo 291.

${ }^{35}$ El nombre de Witold Antonovich Lovsky fue Mendel Nusenovich Mijrovsky (1894-1938), seudónimos: Juan Sherman, Juan El Polaco, José, Mirón, Emile, Raúl, Enrique, Ambrosio, Godoy y Castell. De origen polaco, en su país ingresó al PC, pero tuvo que emigrar a la URSS en 1925. Comenzó a trabajar en la sección latinoamericana de la Profintern, después fue enviado a América Latina a hacer trabajo clandestino. Estuvo
} 
representante de la Confederación Sindical Latinoamericana (CSLA), tuvo una larga conversación con Lombardo Toledano para precisar detalles de los pasos a seguir al convocar a distintas organizaciones obreras del continente participantes del congreso de unificación. Lovsky estaba particularmente interesado en el proyecto de Lombardo Toledano, pues de acuerdo con los lineamientos del VII congreso de la IC era necesario formar los frentes populares, antiimperialistas y antifascistas. Aunque Lombardo Toledano apoyó con entusiasmo la nueva táctica de G. Dimitrov, no tuvo plena coincidencia con la IC porque su interés fue, inicialmente, establecer confederaciones obreras nacionales, con un proyecto de clase, capaz de garantizar derechos laborales y políticos que en muchos de los países de la región aún no se definían del todo, lo que se prestaba para abusos en la incipiente legislación laboral tanto a nivel de la clase patronal, como de los capitalistas foráneos.

Lombardo Toledano, en representación de la CTM, envió su primer mensaje al proletariado de la región, consensuado con Lovsky, a los "siguientes lugares: CSLA, CGT [Confederación General del Trabajo] Argent[ina], FOCH [Federación Obrera de Chile], Legales, CGTU [Confederación General del Trabajo del Uruguay], USU [Unión Sindical Uruguaya], FORU [Federación Obrera Regional Uruguaya], Nueva Central de Paraguay, Colombia y Cuba",36.

El pacto obrero firmado en Santiago de Chile, en enero de 1936, fue el camino inicial que buscó articular a las fuerzas obreras organizadas e independientes en un gran congreso de unificación continental ${ }^{37}$. Lovsky, para apoyar las gestiones de Lombardo Toledano, reclamaba en las cartas enviadas a sus camaradas del Cono Sur que se debía "aprovechar y hay que insistir en que el Pacto no fue una simple cosa de etiqueta"38.

muy relacionado con Cuba y México en los primeros años de la década del 30. Se mantuvo en la isla durante varios meses en la etapa revolucionaria de 1933. En 1934 regresó a Moscú donde informó sobre la revolución cubana en una reunión del Secretariado Latinoamericano el 16 de junio de 1934, y participó en la preparación de los documentos relacionados con la región latinoamericana para el VII Congreso de la IC. En 1935 se relacionó con los movimientos comunistas brasileño, chileno y cubano. Participó en la unificación de los sindicatos en México entre 1935 y 1936. Regresó definitivamente a la URSS a fines de 1936 como ayudante de Alexander Losovsky, pero al poco tiempo fue acusado de trotskista, condenado a la pena de muerte y ejecutado el día 3 de marzo de 1938, véase Lazar Jeifets, Víctor Jeifets, Peter Huber, La Internacional Comunista y América Latina, 1919-1943. Diccionario biográfico, Ginebra, Instituto de Latinoamérica de la Academia de las Ciencias (Moscú) e Institut pour l'histoire du communisme (Ginebra), 2004, p.184 y Olga Ulianova, "Develando un mito: emisarios de la Internacional Comunista en Chile", Historia, núm. 41:1, 2008, pp. 143.

${ }^{36}$ Lovsky, alias Henri, México, 5 de mayo de 1936, RGASPI, fondo 495, serie 10, exp. 357, MP-48.1 (carta dirigida probablemente a la CSLA)

${ }^{37}$ En relación al pacto obrero véase Herrera, "El pacto op. cit., pp. 87-119.

${ }^{38}$ Lovsky, alias Henry, a Tómbola (uno de los seudónimo de Miguel Contreras), México, 26 de mayo de 1936, RGASPI, fondo 495, serie 17, exp. 3. MP-48.1. Rosendo Naula, militante comunista ecuatoriano; Elías Lafertte, Salvador Ocampo, miembros del PC de Chile; Miguel Contreras, miembro del PC argentino y Francisco Pérez Leirós, militante del Partido Socialista argentino, Emilio Frugoni, miembro del Partido Socialista uruguayo, fueron entusiastas colaboradores en el Cono Sur para hacer circular la convocatoria del Congreso Obrero. 
Lombardo Toledano se dejaba apoyar por los miembros del PCM y la CSLA para convocar al Congreso de unidad obrera latinoamericana, pero también sabía que no podía comprometer su independencia como dirigente de la CTM. Hernán Laborde y Lovsky comprendieron esa situación y explícitamente manifestaron a sus camaradas que era perjudicial "denunciar las simpatías y las manos que tenían en este trabajo". El PCM o la CSLA no podían aparecer estar "empujando" a Lombardo Toledano, porque las fuerzas opositoras a su liderazgo y al gobierno de Cárdenas podían aprovechar estos vínculos para cuestionar las estrategias en la conformación de un Frente Popular proletario antiimperialista. Para tales fines era mejor "aprovechar a [Rosendo] Naula de Ecuador [destacado militante comunista] que él interroga a las partes pactantes para que se declaren prestos de seguir actuando a favor de la Unidad" 39 .

En los meses siguientes, Lombardo Toledano prosiguió con su interés por convocar a un congreso obrero regional. Envió telegramas, cartas, mensajes personales a connotados líderes del continente y a las organizaciones sindicales. El dirigente mexicano intentó atraer la solidaridad del movimiento obrero de su país vecino. Su interpelación buscó conmover al proletariado estadounidense con el firme propósito de conseguir la unidad regional del proletariado. El mensaje no escondió sus convicciones: "podéis prestar a la causa de la emancipación del proletariado servicios incomparables [...] Podéis también ayudar a las naciones semicoloniales de la América Latina, cuya vanguardia geográfica y moral la constituye mi país"

La AFL no prestó ninguna colaboración para la instalación del Congreso obrero. William Green manifestó desde un comienzo su rechazo a la iniciativa, por considerarla una maniobra del comunismo internacional. Lovsky exteriorizó su preocupación por la oposición de la AFL, afirmando:

Este problema se torna cada vez más importante en vista de la actitud de Morones como vicepresidente de la COPA, que emprendió un trabajo activo por el desprestigio de la CTM en escala continental. Santiago Iglesias, dirigente de la COPA y funcionario de la Secretaría de Estado de la Casa Blanca, se hace últimamente pasar por izquierdista y en sus declaraciones hace ver que la COPA será lo que querrá el proletariado continental. Siguen empeñándose en la celebración del Congreso [...] Green es quien propicia la COPA y la CTM hace todo lo posible para ganar a Green para la CTM en contra de Morones [...] Nosotros, estando en el sur, hemos pensado equivocadamente que la COPA ya se murió y no existe ya ningún problema $^{41}$.

Green utilizó los medios periodísticos de su país y la prensa mexicana, opositora a Lombardo Toledano, para denostar a los dirigentes que estaban organizando la reunión

\footnotetext{
${ }^{39}$ Lovsky, alias Godoy, a Tómbola, México, 8 de mayo de 1936, RGASPI, fondo 495, serie 17, exp. 3, MP48.1.

${ }^{40}$ Vicente Lombardo Toledano, "Mensaje al proletariado de los Estados Unidos de Norteamérica", Futuro, mayo de 1936.

${ }^{41}$ Carta de Juan [Lovsky] probablemente a la Profintern, México, 15 de mayo 1936, RGASPI Fondo 495, serie 10, exp. 327, MP-48.1.
} 
continental, indicaba que estaban pagados por la Unión Soviética para "defender el comunismo internacional" y que la asamblea no era representativa de la clase obrera de la región. Desde entonces las relaciones con la AFL fueron malas, y a pesar de que Lombardo Toledano los invitó, en los años sucesivos, a los congresos generales y del comité central de la CTM, siempre declinaron a favor de sus "intereses anticomunistas" 42 .

La colaboración internacional para concretar la unidad sindical latinoamericana recibió un fuerte respaldo del estadounidense John L. Lewis, representante del Congreso de Organizaciones Industriales (CIO), y con la incorporación de la CTM a las filas de la Federación Sindical Internacional (FSI), fundada en 1901, y refundiéndose luego del término de la Primera Guerra Mundial, siendo la contraparte de la IC. El ingreso de la CTM a las filas de FSI fue un paso más en la concreción de un proyecto que sumó adeptos con el correr de los meses. Existió la convicción de que el proletariado latinoamericano estaba próximo a inaugurar su asamblea continental, por eso fue recibida con beneplácito en la CTM la propuesta de sumar fuerzas con los trabajadores de otras latitudes: "su ingreso en la Federación Sindical Internacional será, sin duda alguna, una aportación importante [...] especialmente para los trabajadores latinoamericanos [...] que se identifican siempre con la causa de la libertad nacional, dada su estructura de pueblos semicoloniales y de escaso desarrollo económico",43.

Considerada la CTM como la principal fuerza obrera del continente, aproximadamente con un millón de miembros, Lombardo Toledano reiteró la invitación en septiembre de 1936, a través de una extensa carta a las agrupaciones obreras del continente para convocar a reunirse a la brevedad en un Congreso Obrero. Al respecto, el Secretario General de la CTM escribió:

Mientras tanto, hay una tarea que debemos acometer con entusiasmo y sin pérdida de tiempo: la unificación del proletariado [...] todas las reivindicaciones fundamentales de la clase asalariada, dependen, pues, en cada uno de los países latinoamericanos, tanto de la unificación interior del proletariado como de su unidad internacional frente a la fuerza que a todos oprime [...] Nuestra tarea en consecuencia, es clara: convocar sin pérdida de tiempo a un congreso obrero latinoamericano, que establezca las bases y lo objetivos de una lucha continental a favor de los derechos fundamentales del proletariado y de la verdadera autonomía de las veinte naciones ligadas por el mismo destino histórico ${ }^{44}$.

La Confederación General del Trabajo de Argentina (CGTA) comunicó su apoyo definitivo a la CTM en marzo de 1937 para reunir a las organizaciones sindicales del continente en un Congreso Obrero Latinoamericano. La CGTA fue uno de los núcleos más importante de las sindicales existentes en la América del Sur, por esa razón fue oportuno su explícito apoyo

\footnotetext{
${ }^{42}$ Al respecto se puede consultar: FHLT, Id. 18659, legajo 329; La C.T.Ch. y el proletariado de América Latina, Santiago, Editorial Antares, 1939, 28-34.

${ }^{43}$ Comité nacional de la CTM, "Se adhiere la C.T.M. a la Federación Sindical Internacional", Excélsior, México, D. F., 10 de julio de 1936.

${ }^{44}$ Vicente Lombardo Toledano, "Carta de la C.T.M. a las centrales sindicales de América Latina”, México, D. F., septiembre de 1936, en VLT, Obra Histórico-Cronológica, tomo III, volumen 4 op. cit., pp. 348-354.
} 
en materializar un comité organizador del congreso continental. Incluso, la realización del encuentro se planificó para el fin de año de 1937, a realizarse originalmente en Panamá, por ser una localización intermedia que facilitaría la participación de los delegados obreros. La reunión, que congregaría al mayor contingente de representantes obreros de la región, fue calificada como "el baluarte más eficaz con que cuente el proletariado de la América Latina en contra de sus enemigos domésticos y en contra del imperialismo"45. Cada una de las organizaciones obreras del continente comprendió que sin un entendimiento verdadero, sin una alianza eficaz, la lucha por la autonomía económica de cada país era una confrontación estéril. Para Lombardo Toledano, la unidad obrera sólo representó el primer paso, pues luego se asomaba en el horizonte "La lucha por la segunda independencia de los pueblos latinoamericanos [...] una lucha común y simultánea"46.

Las relaciones entre Lombardo Toledano y el PCM desde sus inicios fue tensa y de descalificaciones mutuas. La coyuntura política mexicana los había aproximado, pero las desconfianzas fueron corrientes. Desde la formación de la CTM se agudizaron sus diferencias, y a pesar de que los reclamos por la presencia de León Trotsky en México causaron la impresión de que estaban en la misma trinchera ${ }^{47}$, no logró garantizar del todo las adhesiones recíprocas. Lombardo Toledano visualizó que su cruzada obrera continental estaba siendo amenazada, por causa de las descalificaciones que proferían miembros del PCM. Ante lo cual decidió enviar una extensa carta a Alexander Losovsky ${ }^{48}$, con copia a otros connotados dirigentes comunistas internacionales, entre ellos G. Dimitrov, D. Manuilski y Earl Browder, dando cuenta pormenorizadamente de los obstáculos que el PCM representaba para garantizar la unidad obrera en México y Latinoamérica. Con su decisión de involucrar a la Profintern en el conflicto procuró anticiparse a un quiebre con el PCM, que por momentos pareció inevitable.

Las relaciones se empañaron aún más en el IV Consejo nacional de la CTM, que inició el 27 de abril de 1937, cuando Fidel Velázquez, Secretario de organización y propaganda de la CTM, declaró que no tenían derecho a estar representadas en el consejo varias organizaciones sindicales importantes y rechazó la solicitud de ingreso, arbitrariamente, de federaciones y asociaciones de trabajadores de Querétaro, Nuevo León, Oaxaca y el

\footnotetext{
${ }^{45}$ Informe del comité nacional al IV consejo nacional de la CTM, México, D. F., 27 de abril de 1937, CTM, op. cit.

${ }^{46}$ Vicente Lombardo Toledano, “¿Puede ser considerado México como el molde revolucionario para todos los países de América Latina?”, UO Revista de Cultura Moderna, núm. 15, 1937, México, D. F., Universidad Obrera de México.

${ }^{47}$ En relación a la presencia de Trotsky en México y los reclamos del PCM y Lombardo Toledano, véase: Vera Kuteischikova, "México, Trotsky y la Comintern”, Memoria 105, 1997; Vera Kuteischikova, "México, Trotsky y la Comintern”, Memoria 107, 1998; Olivia Gall, "El papel del PCM y Lombardo op. cit., pp. 615651.

${ }^{48}$ Carta de Vicente Lombardo Toledano a Alexander Losovsky, México, 15 de abril de 1937, RGASPI, fondo 534, serie 7, exp. 399, MP-48.12. El destinatario original de esta misiva por mucho tiempo fue identificado como Earl Browder, cuestión que fue difundida por el Daily Worker (periódico del PC en EE.UU.) y Valentín Campa, histórico dirigente del PCM, en sus Memorias, generando "tendenciosas" interpretaciones sobre la división de la CTM, el quiebre del PCM y la participación de Lombardo Toledano, lo cual ha sido tomado acríticamente por la historiografía.
} 
Distrito Federal. Esta actitud antidemocrática de Velázquez se reafirmó cuando en el mismo consejo aceptó la representación de federaciones obreras de Coahuila, Colima y Aguascalientes, consideradas "postizas y fantasmas" por varios de los delegados, algunos simpatizantes y partidarios del PCM. Las decisiones de Fidel Velázquez produjeron un violento debate, que trajo como resultado inmediato la división de la CTM y el abandono de las sesiones del IV Consejo de los representantes de los grandes sindicatos industriales, como el ferrocarrilero y de electricistas. Lombardo Toledano quedó atrapado en medio del conflicto, no tuvo una acción decidida y fue considerado cómplice de Velázquez por miembros del $\mathrm{PCM}^{49}$.

La IC tuvo que intervenir por intermedio de Earl Browder ${ }^{50}$, Secretario General del PC de Estados Unidos y miembro del comité ejecutivo de la IC, considerado el dirigente comunista más importante en América del Norte, con fuerte influencia en Centroamérica y el Caribe, quien envió una misiva a la dirección del PCM para corregir la errada política de ataques a Lombardo Toledano que estaba quebrando la unidad de la CTM y debilitando las relaciones con el movimiento popular y sindical en América Latina. Browder exigió a la dirigencia del PCM, y a sus bases, establecer una alianza con la CTM y Vicente Lombardo Toledano, sin vacilaciones a partir de la línea estratégica de la IC de Frente Único:

Es necesario buscar un acuerdo con Toledano, y la cooperación de él, haciendo todo lo posible por ayudarlo a corregir sus errores en la práctica, sin tratar de obligarlo a reconocerlos, así como recuperar el prestigio que él ha perdido en importantes sectores de la CTM y fortalecer su personalidad. La consigna del Buró Político debe ser: "UNIDAD DE LA CTM A TODA COSTA", y para asegurar esta unidad, se tendrán que hacer importantes concesiones, empezando por reconocer [...] la autoridad del Comité Nacional encabezado por Lombardo ${ }^{51}$.

En el mes de julio de 1937 el Comité Central del PCM, presidido por Hernán Laborde, en presencia de Earl Browder, resolvió reconocer su responsabilidad en la división de la CTM; respetar los acuerdos del IV Consejo; cooperar con todas las fuerzas políticas y sociales del país para la creación de un frente nacional; y reconocer la autoridad del Consejo ejecutivo de la CTM encabezada por Vicente Lombardo Toledano y Fidel Velázquez; aunque no se logró que volvieran a ser parte de la CTM el Sindicato Industrial de Trabajadores Mineros

\footnotetext{
${ }^{49}$ El conflicto entre el PCM y Vicente Lombardo Toledano se puede consultar en: Miguel Ángel Velasco, "El Partido Comunista durante el periodo de Cárdenas", Gilberto Bosques, Miguel Ángel Velasco y Heberto Castillo, Lázaro Cárdenas, México, Fondo de Cultura Económica, 1975; Guadalupe Pacheco, Arturo Anguiano, Rogelio Vizcaíno, Cárdenas y la izquierda mexicana: ensayo, testimonios y documentos, México, Juan Pablos Editor, 1975; Valentín Campa, Mi testimonio. Memorias de un comunista mexicano, México, Ediciones de Cultura Popular, 1978; Barry Carr, Marxism and Communism in Twentieth Century Mexico, Lincoln, University of Nebraska Press, 1993; Concheiro et al., El comunismo op. cit.; Spenser, "Unidad a toda costa" op. cit.

${ }^{50}$ Para contextualizar la influencia de E. Browder en el comunismo latinoamericano véase Manuel Caballero, La Internacional comunista y la revolución latinoamericana, 1919-1943, Caracas, Editorial Nueva Sociedad, 1987.

${ }^{51}$ Earl Browder, "Informe sobre el Partido Comunista de México" al Sub Comité del Partido Comunista de Estados Unidos, 5 de mayo de 1937, RGASPI, fondo 495, serie 108, exp. 197, MP-48.12.
} 
y Metalúrgicos y el SME. Si bien el conflicto entre las partes logró ser contenido, en la práctica las confianzas se mermaron considerablemente, a tal grado que Lombardo Toledano impuso sus propios términos para alcanzar la unidad obrera nacional y latinoamericana. Al interior del país, la constitución de un frente popular fue coordinada por el Partido Nacional Revolucionario (PNR), a través de la CTM, excluyendo al PCM.

En cuanto a la convocatoria del Congreso Obrero Latinoamericano, el control absoluto fue de Lombardo Toledano, quien orientó las directrices de la convocatoria, seleccionó la invitación de las organizaciones sindicales y planteó un programa preliminar de la reunión, que se efectuó entre el 5-8 de septiembre de 1938, en la ciudad de México. Tanto el PCM como la Profintern fueron desplazados de la primera línea de acción, perjudicando sus pretensiones de control sobre el movimiento obrero de la región y de la instauración de un frente popular antiimperialista de alcance continental.

La contribución de la CTM para concretar la unidad obrera continental estuvo presente desde su instalación. Tanto en los Congresos del Comité Central como en los Congresos Generales de la CTM, entre 1936 y 1938, hubo resoluciones al respecto, que tuvieron como objetivo convocar al máximo de líderes sindicales del continente para establecer criterios comunes en la búsqueda de la unidad de los trabajadores. Fue el propio Lombardo Toledano que se puso a la cabeza de las relaciones internacionales de la CTM, a falta de una estructura administrativa, comunicando en cada instancia los avances en las tratativas para planificar el Congreso Obrero Latinoamericano ${ }^{52}$. Sin la colaboración internacional de la CTM seguramente el camino hacia la unidad obrera regional hubiese tenido contratiempos, aspectos que todavía esperan por una investigación específica y que la historiografía mexicana aún no ha ponderado suficientemente.

\section{Conclusiones}

Las respuestas dadas por la historiografía obrera, todavía en el presente, sobre la participación de Lombardo Toledano en relación a la representación de los trabajadores son insuficientes y "prejuiciadas". Problemas como su rivalidad con Luis N. Morones (CROM), William Green (AFL) o las intervenciones y disputas con el PCM y la Profintern en las planificaciones de la unidad obrera y popular en México y América Latina, han simplificado las experiencias históricas que pudo materializar el dirigente sindical.

La ausencia de análisis templados, además de una investigación de archivo inexistente, proporcionó una interpretación histórica vaciada de contenido sindical, social y político. Planteamiento que se comprende porque las respuestas dadas por los investigadores estuvieron condicionadas por el paradigma de la Guerra Fría, lo cual respondió a una evidente motivación política: los sentimientos anticomunistas o pro-comunistas y el subsiguiente deseo de investigar el grado de influencia comunista en la clase trabajadora

\footnotetext{
${ }^{52}$ Véase CTM op. cit.
} 
del continente. Por ejemplo, la historiografía obrera, de México y América Latina, lo responsabilizó políticamente de los fracasos del PCM. Esta interpretación suele omitir o equiparar las responsabilidades de las cúpulas del PCM (Hernán Laborde, Dionisio Encinas, Valentín Campa, Miguel Ángel Velasco, etc.) con lo realizado por Lombardo Toledano. El tema es que él no militó en el PCM, entonces su colaboración con el partido no puede ser evaluada como parte de la mesa directiva. Fueron los integrantes del Comité Central del PCM quienes trataron de integrarlo a sus líneas de acción y disciplina, pues conocían de su ascendencia entre los obreros, intelectuales y miembros de la burguesía reformista, cuestión que ningún dirigente del PCM estaba en condición de disputarle. De hecho contemporáneamente Hernán Laborde reconoció muchos de estos aspectos, que la historiografía ha pasado por alto, afirmando que Lombardo Toledano no era comunista y que por momentos el PCM exageró la influencia sobre sus acciones ${ }^{53}$. En esa misma dirección Vittorio Codovilla, en un informe confidencial, conocedor de la orientación política de Lombardo Toledano, expresó la necesidad de atraerlo a las filas del PCM ${ }^{54}$.

Por tanto, las fuentes consultadas exhiben a un Lombardo Toledano menos dependiente del PCM, lo que varía las representaciones que la historiografía obrera, particularmente en su versión mexicana, ha sostenido invariablemente por décadas. Seguramente la prensa antilombardista del periodo (El Machete, Excélsior y Novedades) contribuyó para identificar al dirigente sindical como un destacado dirigente comunista, mexicano e internacional, cuestión que se ha matizado en forma relevante en este artículo, pues el acceso a nuevas fuentes nos permiten resituar el periodo y ponderar los altos y bajos de su relación con el PCM y la IC.

La participación activa de Lombardo Toledano en el escenario latinoamericano debe explicarse, entre otras muchas razones, porque tuvo una consolidada posición como dirigente sindical, político e intelectual en la región, al menos desde 1930, que a través de sus viajes a congresos, conferencias y visitas de reconocimiento de la situación política continental e internacional, le habían granjeado la simpatía de importantes líderes obreristas y militantes de la izquierda latinoamericana. Sus cartas con Emilio Frugoni (Uruguay), Francisco Pérez Leirós (Argentina), Óscar Schnake (Chile), Guillermo Polo Medrano (Perú), Rosendo Naula (Ecuador), entre muchos otros, forman parte de sus estrechos vínculos que esperan por investigaciones específicas.

Creemos que el periodo histórico de Lombardo Toledano, como representante de la clase obrera mexicana y continental, debe apoyarse en modelos explicativos más complejos, que relacionen actores, líneas de pensamiento y despliegue de acciones que se comparten más allá de las fronteras del pensamiento ideológico o político. Por ejemplo, el apoyo que le expresó la Profintern para movilizar la unidad obrera regional, en su carácter de marxista internacionalista; la alianza tácita que estableció con Franklin D. Roosevelt para

\footnotetext{
${ }^{53}$ Informe del compañero Hernán Laborde al pleno del Comité Central del Partido Comunista de México, sin fecha (probablemente mayo o junio de 1937), Fondo 495, serie 17, exp, 200, MP-48.1.

${ }^{54}$ Intervención del camarada Pérez [Vittorio Codovilla] ante el C.C. del PCM (estrictamente confidencial), México, 14 de diciembre de 1939, RGASPI, Fondo 495, serie 17. Exp. 222, MP-48.1.
} 
desplazarse por toda América para fustigar el nazifascismo; o el apoyo reciproco que se tributaron con Henry Wallace, vicepresidente de Estados Unidos, y que fue un "trampolín" para la carrera presidencial que ambos sostuvieron en su respectivos países, son todos aspectos que deben considerarse en los estudios históricos.

Las fuentes de archivos, trabajadas en nuestra investigación, exhiben que varios acontecimientos materializados por el dirigente mexicano están estrechamente ligados por los procesos transnacionales y transcontinentales. Vicente Lombardo Toledano fue un actor político de una época que experimentó una transición hacia un mundo con nuevos lenguajes y formaciones sociales que promovieron originales contratos sociopolíticos. Por ejemplo, como representante de la clase trabajadora de América Latina tuvo claro desde un comienzo que la organización no debía estar restringida a las coyunturas locales y menos depender de los ciclos políticos y los partidos ${ }^{55}$.

La unidad de los trabajadores latinoamericanos, promovida por Vicente Lombardo Toledano, no supuso el pensamiento único de sus asociados, menos un programa monolítico o la eliminación de los faccionalismos. Siguiendo muy de cerca el pensamiento de Marx, el dirigente sindical quiso hacerse parte de la premisa que "del lado del obrero, su única fuerza es su masa. Pero la fuerza de la masa se rompe por la desunión",56.

Recibido: 29 agosto 2015

Aceptado: 7 octubre 2015

\section{Archivos}

Archivo Estatal Ruso de la Historia Social y Política (RGASPI)

Archivo Histórico, El Colegio de Michoacán

Archivo Oficina Internacional del Trabajo (AOIT)

Fondo Histórico Lombardo Toledano (FHLT)

\section{Libros y artículos consultados}

\footnotetext{
55 James Wilkie y Edna Monzón, México visto en el siglo XX. Entrevistas de historia oral, México, Instituto mexicano de investigaciones económicas, 1969, p. 359.

${ }^{56}$ Vicente Lombardo Toledano, Teoría y práctica del movimiento sindical mexicano, México, D. F., Editorial Magisterio, 1961, véase capítulos 1 y 3.
} 
Anguiano, Arturo, El Estado y la política obrera del cardenismo, México, Era, 1975.

Caballero, Manuel, La Internacional comunista y la revolución latinoamericana, 19191943, Caracas, Editorial Nueva Sociedad, 1987.

Campa, Valentín, Mi testimonio. Memorias de un comunista mexicano, México, Ediciones de Cultura Popular, 1978.

Cárdenas antes los problemas de México, México, D. F., Comité de Orientación Popular, 1935.

Barry Carr, Marxism and Communism in Twentieth Century Mexico, Lincoln, University of Nebraska Press, 1993.

Chassen de López, Francie, Lombardo Toledano y el movimiento obrero mexicano (19171940), México, Editorial Extemporáneos, 1977.

Córdova, Arnaldo, La clase obrera en la historia de México: en una época de crisis (19281934), México, Siglo XXI editores, 1980.

Córdova, Arnaldo, La política de masas del cardenismo, México, Era, 1974.

CTM 1936-1941, México, 1941.

Gall, Olivia, "El papel del PCM y Lombardo en la guerra del Kremlin, la Comintern y la GPU contra Trotsky, México 1936-1940", Elvira Concheiro, Massimo Modonesi y Horacio Crespo (Coord.), El comunismo: otras miradas desde América Latina, México, UNAM, 2007.

Herrera González, Patricio "Vicente Lombardo Toledano: nexo entre los obreros latinoamericanos y la OIT", Trabajadores, núm. 91, 2012, pp. 23-29.

Herrera González, Patricio, "La Confederación de Trabajadores de América Latina en la historiografía obrera, 1938-1963”, Cuadernos de Historia, núm. 36, 2012, pp. 85-117.

Herrera González, Patricio, "En favor de una Patria de los trabajadores". La Confederación de Trabajadores de América Latina y su lucha por la emancipación del continente, 1938-1953. Tesis de Doctor en Historia, Centro de Estudios Históricos, El Colegio de Michoacán, Zamora, México, 2013 (Inédita).

Herrera González, Patricio, "La Confederación de Trabajadores de América Latina y la implementación de su proyecto sindical continental (1938-1941)", Trashumante, núm. 2, 2013, pp. 136-164. 
Herrera González, Patricio, "La primera conferencia regional del trabajo en América: su influencia en el movimiento obrero, 1936", Fabián Herrera León y Patricio Herrera González (Coord.), América Latina y la Organización Internacional del Trabajo. Redes, cooperación técnica e institucionalidad social, 1919-1950, Morelia, Instituto de Investigaciones Históricas, Universidad Michoacana de San Nicolás de Hidalgo, 2013, pp. 199-242.

Herrera González, Patricio, "El pacto por la unidad obrera continental: sus antecedentes en Chile y México, 1936", Estudios de Historia Moderna y Contemporánea de México, núm. 46, 2013, pp. 87-119.

Herrera González, Patricio, "Vicente Lombardo Toledano y el Congreso Obrero Latinoamericano (1935-1938)”, Relaciones, núm. 138, 2014, pp. 109-150.

Jeifets, Lazar, Víctor Jeifets, Peter Huber, La Internacional Comunista y América Latina, 1919-1943. Diccionario biográfico, Ginebra, Instituto de Latinoamérica de la Academia de las Ciencias (Moscú) e Institut pour l'histoire du communisme (Ginebra), 2004.

Krauze, Enrique, Caudillos culturales de la Revolución Mexicana, México, D. F., Siglo XXI Editores, 1976.

La C.T.Ch. y el proletariado de América Latina, Santiago, Editorial Antares, 1939.

León, Samuel e Ignacio Marván, La clase obrera en la historia de México: en el Cardenismo (1934-1940), México, Siglo XXI editores, 1985.

León, Samuel, "El comité nacional de defensa proletaria", Revista Mexicana de Sociología, vol. 40, núm. 2, 1978, pp. 729-762.

Lombardo Toledano, Vicente y Víctor Manuel Villaseñor, Un viaje a un mundo del porvenir (Seis conferencias sobre la U.R.S.S.), México, Universidad Obrera de México, 1936.

Lombardo Toledano, Vicente, “¿Puede ser considerado México como el molde revolucionario para todos los países de América Latina?", UO Revista de Cultura Moderna, núm. 15, julio-septiembre de 1937.

Lombardo Toledano, Vicente, "Mensaje al proletariado de los Estados Unidos de Norteamérica", Futuro, mayo de 1936.

Lombardo Toledano, Vicente, La Doctrina Monroe y el Movimiento Obrero, México, Talleres Linotipográficos La Lucha, 1927. 
Lombardo Toledano, Vicente, Obra Histórico-Cronológica, tomo II, volumen 4, México, Centro de Estudios Filosóficos, Sociales y Políticos Vicente Lombardo Toledano, 1995.

Lombardo Toledano, Vicente, Obra Histórico-Cronológica, tomo III, volumen 4, México, Centro de Estudios Filosóficos, Políticos y Sociales Vicente Lombardo Toledano, 1996.

Lombardo Toledano, Vicente, Teoría y práctica del movimiento sindical mexicano, México, D. F., Editorial Magisterio, 1961.

Pacheco, Guadalupe, Arturo Anguiano, Rogelio Vizcaíno, Cárdenas y la izquierda mexicana: ensayo, testimonios y documentos, México, Juan Pablos Editor, 1975.

Spenser, Daniela, "El viaje de Vicente Lombardo Toledano al mundo del porvenir", Desacatos, núm. 34, 2010, pp. 77-96.

Spenser, Daniela, "Unidad a toda costa": La Tercera Internacional en México durante la presidencia de Lázaro Cárdenas, México, CIESAS, Publicaciones de la Casa Chata, 2007.

Velasco, Miguel, "El Partido Comunista durante el periodo de Cárdenas", Bosques, Gilberto, Miguel Ángel Velasco y Heberto Castillo, Lázaro Cárdenas, México, Fondo de Cultura Económica, 1975.

Ulianova, Olga, "Develando un mito: emisarios de la Internacional Comunista en Chile", Historia, núm. 41:1, 2008, pp. 99-164.

Vera, Kuteischikova, “México, Trotsky y la Comintern”, Memoria 105, 1997.

Vera, Kuteischikova, “México, Trotsky y la Comintern”, Memoria 107, 1998.

Wilkie James y Edna Monzón, México visto en el siglo XX. Entrevistas de historia oral, México, Instituto mexicano de investigaciones económicas, 1969. 